\title{
Modelling of the Relationship of Adiabatic Shear and Cutting Conditions for Higher Cutting Speed Ranges
}

\author{
Guohe Li* - Yujun Cai - Houjun Qi - Meng Liu \\ Tianjin University of Technology \& Education, Tianjin Key Laboratory of High-speed Cutting \& Precision Machining, China
}

The serrated chip is a typical characteristic of high-speed cutting due to the occurrence of adiabatic shear. Based on an adiabatic shear sensitivity index proposed via linear perturbation analysis, which considers the pressure-shear condition in machining, the relationship of adiabatic shear and cutting conditions is established. The corresponding relation between the cutting conditions and the deformation conditions is established based on the model of a parallel boundary shear zone. The influence of cutting parameter on adiabatic shear is analysed, and the results show that the adiabatic shear in high speed machining tends to occur under the condition of higher cutting speed, greater depth of cut and smaller rake angle. An orthogonal cutting experiment was performed to validate the proposed model. Furthermore, the influence mechanism of cutting conditions on adiabatic shear is discussed in detail, and one application of the model is introduced.

Keywords: high speed machining, adiabatic shear, linear perturbation analysis, cutting parameter

Highlights

- $\quad$ The relationship of adiabatic shear and cutting conditions was established.

- The influence of cutting parameter on adiabatic shear is analysed.

- An orthogonal cutting experiment was carried out to validate the proposed model.

\section{INTRODUCTION}

High-speed machining (HSM) has a series of advantages, such as smaller cutting force, higher precision, better surface quality, higher productivity, lower cost, and it can be used for difficult-to-process materials. Therefore, it is extensively applied in the fields of aerospace, automotive and moulding, etc., and is widely used [1]. The main difference between high speed cutting and conventional cutting is that the serrated chip is often produced in high speed cutting [2] and [3], and the continuous chip is produced in conventional cutting. Fig. 1 shows diagrams of a continuous chip and serrated chip. Although some scholars ascribed the occurrence of serrated chips to a periodic crack initiated in the free surface of the workpiece ahead of the tool [4] and [5]. Other researchers, including Recht [6], Komandui [7], Davies [8], Molinari [9] and Ma [10], attributed the formation of serrated chips to a repeated thermo-plastic instability occurring in the primary shear zone, particularly for ductile materials [2] and [11]. On one side, the occurrence of adiabatic shear in high speed cutting will increase the tool wear and influence the quality of the finished surface. On the other side, it is beneficial to the rupture of chip and favourable automation machining. Therefore, in order to control the cutting process effectively, more attention should be paid to the adiabatic shear localization in HSM.
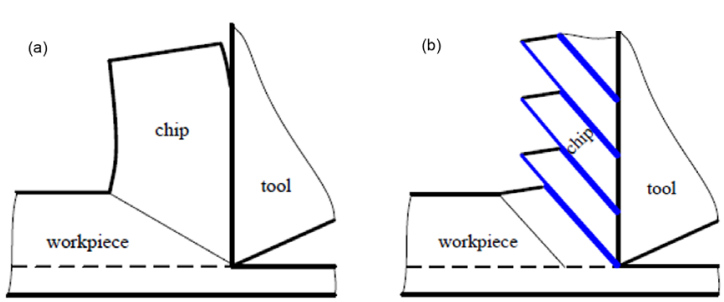

Fig. 1. Sketch map of chip:

a) continuous chip, and b) serrated chip

Extensive research has been conducted on adiabatic shear in the machining of various materials. Sun et al. [12] examined the chip formation during the dry turning of Ti6Al4V in association with dynamic cutting force measurements under different cutting speeds, feed rates, and depths of cut. Huang et al. [13] carried out the perturbation analysis of thermoviscoplastic instability in chip formation to establish the relation for the segment spacing which was obtained by multiplying the chip flow velocity by the characteristic time of instability. Duan and Zhang [14] presented an in-depth investigation into the formation mechanisms and microstructures of adiabatic shear bands (ASBs) in hardened AISI 1045 steel induced by HSM. A systematic analysis, both experimental and theoretical, showed that a low cutting speed leaded to deformed ASBs, and a high cutting speed resulted in transformed ASBs. Molinari et al. [15] investigated the role of cutting conditions on adiabatic shear banding and chip serration by combining 
finite element calculations and analytical modelling. Miguélez et al. [16] focused on the numerical analysis of adiabatic shear banding in orthogonal cutting of Ti6Al4V alloy. The influence of cutting velocity and feed in chip segmentation was studied. Moreover, the role of friction at the tool-chip interface and the effect of rheological parameters of the constitutive equation were analysed. Gu et al. [17] investigated the damage evolution mechanism of adiabatic shear localized fracture (ASLF) in chip formation under an optical microscope and scanning electron microscope (SEM) through an HSM experiment of hardened AISI 1045 steel at a relatively high cutting speed. They further investigated the induced mechanism of adiabatic shear fracture and the corresponding damage process in high-speed machining through quick-stop tests and chip morphology examinations [18]. On the basis of saturation limit model, the critical fracture energy was predicted by cutting conditions and compared with the experimental results. Ye et al. [3] set up an experimental device, based on the light-gas gun technology, to realize high speed cutting over a wide range of cutting speed from $30 \mathrm{~m} / \mathrm{s}$ to $200 \mathrm{~m} / \mathrm{s}$. Highspeed cutting experiments were performed on AISI 1045 steel. The investigation of chip morphology, micro-structure, micro-hardness and the finished surface integrity were carried out. Furthermore, they performed the cutting experiments on Ti6Al4V alloy over a wide range of cutting speed [19]. The transition of chip morphology from continuous to serrated was observed with increasing the cutting speeds. A new theoretical model was developed to predict the segment spacing, in which the momentum diffusion due to unloading within the shear band had been considered. They also proposed an explicit expression of the critical cutting speed for the onset of serrated chip flow, which is given in terms of material properties, uncut chip thickness and tool rake angle, based on dimensional analysis and numerical simulations. It could give reasonable predictions of the critical cutting speeds at which chips change from continuous to serrated chip for various metallic materials over wide ranges of uncut chip thickness and tool rake angle [20]. Recently, Ye et al. [21] systematically analysed the experimental results of high-speed cutting on various typical metallic materials over wide ranges of cutting speeds. By considering the coupling effects of inertial, tool-chip compression and material convection, the critical condition for the onset of serrated chip flow was determined based on a stability analysis of the deformation inside the primary shear zone. It is found that the emergence of the serrated chip flow is dominated by a dimensionless number that characterized the competition among the effects of inertia, thermal softening, strain hardening, elastic unloading, viscous diffusion and thermal diffusion. Wang et al. [22] studied the formation condition of continuous and saw-tooth chips and various characteristics of the saw-tooth chip, such as cutting speed, feed rate, axial depth of cut, and others. The results showed that the chip of materials with different hardness could be controlled to the continuous chip through the optimization of a combination of cutting speed, feed per tooth, and depth of cut. $\mathrm{Wu}$ and Sandy [23] investigated the cutting mechanism of a new emerging high temperature and high strength titanium alloy named TC21 using the finite element method (FEM), a modified high temperature split Hopkinson pressure bar (SHPB) test system was employed to obtain the stress-strain curves of TC21 alloy under different temperatures and strain rates. Jomaa et al. [24] developed a 2D FEM based on a Lagrangian approach for simulating and analysing the serrated chip formation during HSM of the AA7075-T651 alloy. Wang and Liu [25] presented an investigation of chip morphology from the viewpoint of a chip-free surface and cross-section. The research showed that the microstructure of chip-free surface evolves from lamellae to folds and then to dimples. According to the experimental results, a new model of serrated chip formation based on mixed mode of ductile fracture and adiabatic shear was proposed. They further investigated the influence mechanism of stress triaxiality on the serrated chip formation during HSM [26]. The fracture loci of ASBs in serrated chips under different cutting speeds have been obtained and validated by experimental results. The research has proven that the stress triaxiality plays a vital role in serrated chip formation during HSM. They also found that the chip serrated frequencies for the two work-piece materials during HSM are found to be nearly equal to their corresponding AE-dominant frequencies [27]. These pioneering works give important indications to study the influence of cutting parameters on adiabatic shear in HSM.

In the next section, the pressure-shear stress state of the primary shear zone to build the continuum mechanics basic equations of machining is considered. An adiabatic shear sensitivity index is proposed by linear perturbation analysis. In Section 2, the model of deformation conditions in shear plane $\mathrm{AB}$ based on the model of parallel boundary shear zone is presented so as to build the corresponding relations between the deformation conditions and the cutting parameters of orthogonal cutting (i.e. cutting speed, depth of cut, and rake angle). In Section 3, AISI 1045 steel is taken as an 
example to analyse the influence of cutting parameter on adiabatic shear according to the adiabatic shear sensitivity index. An orthogonal cutting experiment was carried out and the changes of chip with cutting parameters were shown to validate the analysis results in Section 4. The influence mechanism of cutting parameters on adiabatic shear is discussed in detail in Section 5. The concluding remarks of the paper are Section 6.

\section{ADIABATIC SHEAR SENSITIVITY INDEX}

It is usually thought that the deformation in HSM is a plane strain because the width of cut $a_{w}$ is far greater than the depth of cut $a_{c}$. Stable cutting is assumed and the built-up edge is neglected. The narrow zone in Fig. 2, named as CAEFBD, is the primary shear zone with length of $2 l$ and width of $s$. Where the CD plane and EF plane are the upper and lower boundaries of the primary deformation zone respectively. The $A B$ plane in the middle of the primary deformation zone, is the shear plane. The deformation in each plane that is parallel to $\mathrm{AB}$ is homogeneous. The inclination between the shear plane $\mathrm{AB}$ and cutting speed $V$ is the shear angle $\phi \cdot \gamma_{1}$ is the rake angle of cutting tool. $\tau_{\mathrm{CD}}$, $\tau_{\mathrm{AB}}$ and $\tau_{\mathrm{EF}}$, are the shear stress of $\mathrm{CD}, \mathrm{AB}$, and $\mathrm{EF}$ plane, respectively. $\sigma_{\mathrm{AB}}$ is the compression stress of shear plane AB. $F_{r}$ is the cutting force. $F_{s}$ and $F_{n s}$ are the component forces along and perpendicular to the shear direction, respectively. $F_{r}{ }^{\prime}$ is the reaction force of $F_{r} . F_{f}$, and $F_{n}$ are the friction force and pressure force on rake face. Therefore, there is a pressure-shear stress state in the primary deformation zone, as shown in Fig. 3.

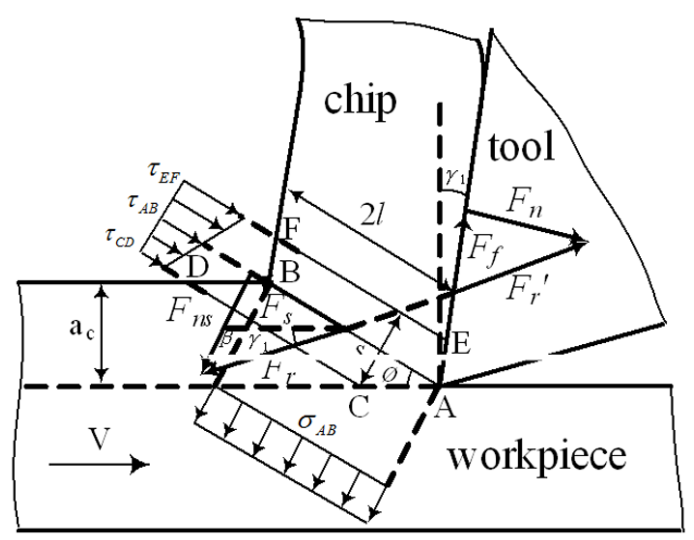

Fig. 2. Model of orthogonal high-speed machining

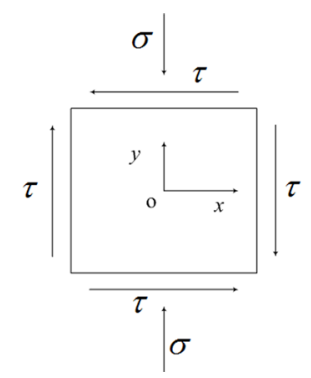

Fig. 3. Stress state of the primary shear zone

According to the stress state of the primary deformation zone, the basic foundations of continuum mechanics in HSM for the coordinate system in Fig. 3 are as follows,

$$
\left\{\begin{array}{l}
\rho \frac{\partial v_{x}}{\partial t}=\frac{\partial \tau}{\partial y} \\
\rho \frac{\partial v_{y}}{\partial t}=\frac{\partial \sigma}{\partial y} \\
\rho c \frac{\partial T}{\partial t}=k \frac{\partial^{2} T}{\partial y^{2}}+\beta \sigma \frac{\partial v_{y}}{\partial y}+\beta \tau \frac{\partial v_{x}}{\partial y}
\end{array}\right.
$$

where $v_{x}, v_{y}$ are the velocity component, $\tau$ is the shear stress, $\sigma$ is the compressive stress, $T$ is the temperature, $\rho$ is the density, $c$ is the thermal capacity, $k$ is the thermal conductivity, $\beta$ is the Taylor-Quinney coefficient, $t$ is time and $x, y$ are coordinate axes. According to material mechanics, $\dot{\gamma}=\left(\partial v_{x} / \partial y\right)+\left(\partial v_{y} / \partial x\right)$ and $\dot{\varepsilon}=\left(\partial v_{x} / \partial x\right)+\left(\partial v_{y} / \partial y\right)$, and in the primary deformation zone, $\partial v_{y} / \partial x=0$ and $\partial v_{x} / \partial x=0$, so $\dot{\gamma}=\partial v_{x} / \partial y$, and $\dot{\varepsilon}=\partial v_{y} / \partial y$. The constitutive relation is expressed as $\tau=f(\gamma, \dot{\gamma}, T)$. Thus, the equation can be expressed by,

$$
\left\{\begin{array}{l}
\rho \frac{\partial^{2} \gamma}{\partial t^{2}}=\frac{\partial \tau}{\partial y} \\
\rho \frac{\partial^{2} \varepsilon}{\partial t^{2}}=\frac{\partial \sigma}{\partial y} \\
\rho c \frac{\partial T}{\partial t}=k \frac{\partial^{2} T}{\partial y^{2}}+\beta \sigma \frac{\partial \varepsilon}{\partial t}+\beta \tau \frac{\partial \gamma}{\partial t}
\end{array} .\right.
$$

The linear perturbation analysis of Eq. (2) is carried out, and more detail can be seen in [28]. Then the homogeneous system of equations,

$$
\left\{\begin{array}{l}
{\left[\rho \alpha^{2}+\left(Q_{0}+R_{0} \alpha\right) k^{\prime 2}\right] \gamma_{*}-P_{0} k^{\prime 2} T_{*}=0} \\
{\left[\rho \alpha^{2}+\left(Q_{0}+R_{0} \alpha\right) k^{\prime 2}\right] \varepsilon_{*}-P_{0} k^{\prime 2} T_{*}=0} \\
{\left[\beta \tau_{0} \alpha+\beta \dot{\gamma}_{0}\left(Q_{0}+R_{0} \alpha\right)\right] \gamma_{*}+\left[\beta \sigma_{0} \alpha+\beta \dot{\varepsilon}_{0}\left(Q_{0}+R_{0} \alpha\right)\right] \varepsilon_{*}-} \\
-\left(\beta \dot{\gamma}_{0} P_{0}+\beta \dot{\varepsilon}_{0} P_{0}+\rho c \alpha+k k^{\prime 2}\right) T_{*}=0
\end{array}\right.
$$




$$
\left|\begin{array}{ccc}
\rho \alpha^{2}+\left(Q_{0}+R_{0} \alpha\right) k^{\prime 2} & 0 & -P_{0} k^{\prime 2} \\
0 & \rho \alpha^{2}+\left(Q_{0}+R_{0} \alpha\right) k^{\prime 2} & -P_{0} k^{\prime 2} \\
\beta \tau_{0} \alpha+\beta \dot{\gamma}_{0}\left(Q_{0}+R_{0} \alpha\right) & \beta \sigma_{0} \alpha+\beta \dot{\varepsilon}_{0}\left(Q_{0}+R_{0} \alpha\right) & \beta \dot{\gamma}_{0} P_{0}+\beta \dot{\varepsilon}_{0} P_{0}+\rho c \alpha+k k^{\prime 2}
\end{array}\right|=0 .
$$

where $\gamma_{*}, \tau_{*}, T_{*}, \varepsilon_{*}, \sigma_{*}$ is the amplitude, $\alpha$ is the growth rate and $k^{\prime}$ is the wave number.

To guarantee the existence of non-trivial solutions for $\gamma_{*}, \varepsilon_{*}$ and $T_{*}$, the determinant of the coefficients matrix in Eq. (3) should be zero: specifically presented in Eq. (4).

This leads to the characteristic cubic equation:

$$
\begin{aligned}
& \rho^{2} c \alpha^{3}+\rho\left[\beta P\left(\dot{\gamma}_{0}+\dot{\varepsilon}_{0}\right)+\left(k+c R_{0}\right) k^{\prime 2}\right] \alpha^{2}+ \\
& +\left[k R_{0} k^{\prime 2}+\rho c Q_{0}-\beta\left(\tau_{0}+\sigma_{0}\right) P_{0}\right] k^{\prime 2} \alpha+k Q_{0} k^{\prime 4}=0 .
\end{aligned}
$$

This is a spectral equation. A positive real root of $\alpha$ implies that instability is possible. The criterion condition of the adiabatic shear in high-speed cutting can be given through the discussion of the stability of spectral equation [28], and as follows:

$$
B=\frac{\eta P_{0} \sqrt{\sigma^{2} / 3+\tau^{2}}}{\rho c Q_{0}}-2 \sqrt{\frac{\eta k P_{0} \dot{\gamma}_{0}}{\rho c^{2} Q_{0}}} \geq 1 .
$$

Eq. (6) shows that the influence factors of adiabatic shear in HSM are material characteristics and deformation conditions. The value of parameter $B$ reflects the degree of adiabatic shear evolution and can be taken as the adiabatic shear sensitivity index. The deformation condition of HSM is determined by cutting parameters. If the corresponding relations between the cutting parameters and the deformation conditions can be established, the relationship between cutting parameters and adiabatic shear can be given.

\section{MODEL OF DEFORMATION CONDITION IN THE PRIMARY SHEAR ZONE}

We can use the method of lattice line or streamline to get the distribution of strain rate in machining. The analysis results of these two methods showed that the distribution of the strain rate in the primary shear zone nears to a quadratic curve [29] and [30], as shown in Fig. 4.

If the coordinate of Fig. 5 is adopted, the strain rate distribution in the primary shear zone can be expressed as follows:

$$
\dot{\gamma}(z)=\frac{2 a V \sin \phi}{\left[(s / 2-z)^{2}+(s / 2)^{2}\right]^{3 / 2}},
$$

where $s$ is the width of the primary shear zone, and

$$
a=\frac{s^{2}}{16 \sin ^{2} \phi\left(\operatorname{tg} \gamma_{1}+\operatorname{ctg} \phi\right)} \text {. }
$$

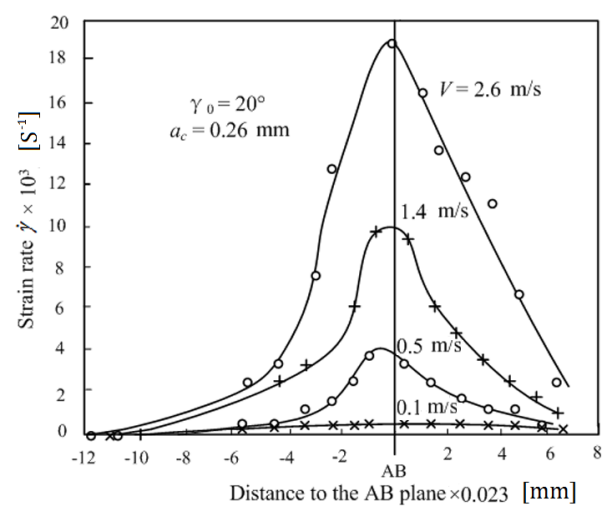

Fig. 4. Strain rate distribution

From Fig. 4, we can see that the strain rate of $\mathrm{AB}$ plane is maximum. According to the adiabatic shear theory, the adiabatic shear should occur in $A B$ plane first. Therefore, in this paper, the deformation conditions of $\mathrm{AB}$ plane are taken as that leads to the adiabatic shear in HSM.

On the $\mathrm{AB}$ shear plane, $z=s / 2$, so the strain rate of $\mathrm{AB}$ plane can be calculated as follows:

$$
\begin{aligned}
\dot{\gamma}_{\mathrm{AB}} & =\frac{2 a V \sin \phi}{\left[\left(\frac{s}{2}-\frac{s}{2}\right)^{2}+\left(\frac{s}{2}\right)^{2}\right]^{3 / 2}}= \\
& =\frac{2 V \sin \phi \times s^{2}}{\frac{s^{2}}{8} \times 16 \sin ^{2} \phi\left(\operatorname{tg} \gamma_{1}+\operatorname{ctg} \phi\right)}=\frac{V \cos \gamma_{1}}{s \cos \left(\phi-\gamma_{1}\right)} .
\end{aligned}
$$

When Eq. (8) is used to calculate the strain rate of $\mathrm{AB}$ plane, in the first place, the width of the primary shear zone $s$ and the shear angle $\phi$ should be known.

If the deformation coefficient is defined as follows,

$$
\xi=a_{c h} / a_{c},
$$

where the $a_{c h}$ is the thickness of chip and $a_{c}$ is the depth of cut. Then, the shear angle can be calculated as follows, 


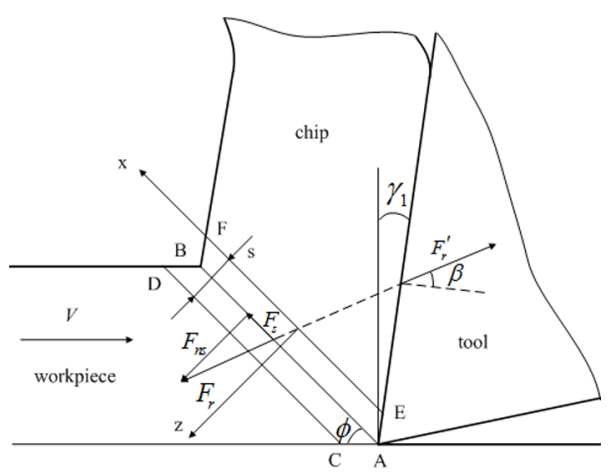

Fig. 5. Coordinate and cutting force

$$
\operatorname{tg} \phi=\frac{\cos \gamma_{1}}{\xi-\sin \gamma_{1}}
$$

The thickness of chip usually decreases with the increase of cutting speed, so the deformation coefficient $\xi$ decreases with the increase of cutting speed (Fig. 6), and it will be close to 1 when the cutting speed is higher because the thickness of chip is impossible less than depth of cut under the condition of continuous chip is produced. Our work [31] on the experiment of hardened AISI 1045 steel and the work of Komanduri and Von Turkovich [32] on Ti6Al4V demonstrated this phenomenon. Therefore, the deformation coefficient is assumed as 1 in this paper, and the shear angle $\phi$ can be calculated by Eq. (10).

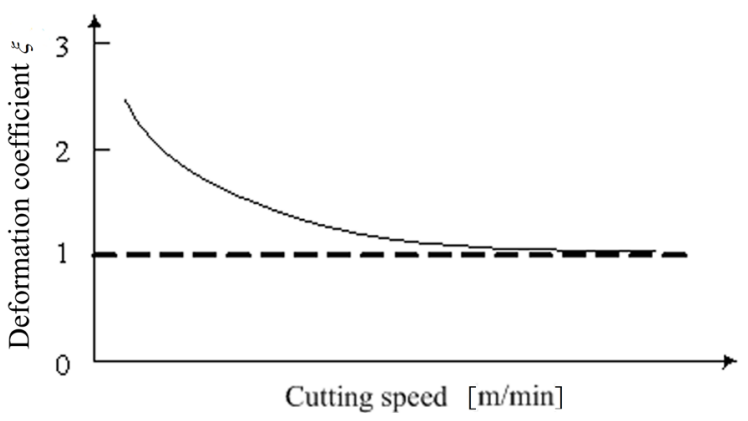

Fig. 6. Change of deformation coefficient with cutting speed

For the width of the primary shear zone, the study of Oxley and Hastings [33] shows that the ratio of it and the length of shear plane is 5.9 for carbon steel; thus, there is,

$$
s=a_{c} /(5.9 \sin \phi) .
$$

The distribution of strain can be acquired by integrating the distribution of strain rate (Eq. (7)) and the result is,

$$
\gamma(z)=\frac{8 a(z-s / 2)+\sqrt{(z-s / 2)^{2}+(s / 2)^{2}}}{s^{2} \sqrt{(z-s / 2)^{2}+(s / 2)^{2}}} .
$$

On the shear plane $\mathrm{AB}, z=s / 2$, we get the strain of AB plane as follow,

$$
\gamma_{\mathrm{AB}}=\frac{1}{2} \frac{\cos \gamma_{1}}{\sin \phi \cos \left(\phi-\gamma_{1}\right)} .
$$

The distribution of temperature in the primary shear zone can be obtained through the method of non-uniform volume moving heat source, the detail of this method can be found in reference [34]. According to this method, the temperature of $A B$ plane can be obtained by:

$$
T_{\mathrm{AB}}=T_{0}+\frac{\tau(z)}{\rho c V \sin \phi} \int_{0}^{s / 2} R(z) \dot{\gamma}(z) d z,
$$

where $T_{0}$ is the ambient temperature, $\tau(z)$ is the shear stress, and it can be calculated by the constitutive relationship $\tau(z)=f(\gamma(z), \dot{\gamma}(z), T(z)) . R(z)$ is the coefficient of heat transmission, which can be calculated with the temperature at the same time.

According to the relationship between the cutting force and the shear angle in Fig. 7, it can be seen that,

$$
F_{r}=\frac{F_{s}}{\cos \left(\phi+\beta-\gamma_{1}\right)}=\frac{\tau A_{c}}{\sin \phi \cos \left(\phi+\beta-\gamma_{1}\right)},
$$

and

$$
F_{n s}=F_{r} \sin \left(\phi+\beta-\gamma_{1}\right) .
$$

Thus, the compression stress can be expressed as follows:

$$
\begin{aligned}
\sigma & =\frac{F_{n s}}{A_{s}}=\frac{F_{r} \sin \left(\phi+\beta-\gamma_{1}\right) \sin \phi}{A_{c}}= \\
& =\tau \cdot \operatorname{tg}\left(\phi+\beta-\gamma_{1}\right) .
\end{aligned}
$$

According to Merchant's formula of shear angle, there is,

$$
\phi+\beta-\gamma_{1}=\pi / 4
$$

Therefore, the expression of compression stress becoming,

$$
\sigma_{\mathrm{AB}}=\tau_{\mathrm{AB}},
$$

where $\tau_{\mathrm{AB}}=f\left(\gamma_{\mathrm{AB}}, \dot{\gamma}_{\mathrm{AB}}, T_{\mathrm{AB}}\right)$ and can be calculated by a constitutive relationship. 


\section{INFLUENCE OF CUTTING PARAMETERS ON ADIABATIC SHEAR IN HSM}

Now, the influence of cutting parameters on adiabatic shear in HSM can be analysed based on the model proposed. Where AISI 1045 steel is taken as an example and its constitutive relationship is expressed by the Johnson-Cook model, considering that the $\tau=\sigma / \sqrt{3}$ and $\gamma=\sqrt{3} \varepsilon$, its expression is as follows,

$\tau=\frac{1}{\sqrt{3}}\left[\bar{A}+\bar{B}\left(\frac{\gamma}{\sqrt{3}}\right)^{n}\right]\left[1+\bar{C} \ln \left(\frac{\dot{\gamma}}{\dot{\gamma}_{r}}\right)\right]\left[1-\left(T^{*}\right)^{m}\right]$,

where $\bar{A}, \bar{B}, \bar{C}, n$ and $m$ are parameters of constitutive relationship and their value are shown in Table 1 [35], $\dot{\gamma}_{r}$ is the reference strain rate. $T^{*}=\left(T-T_{r}\right) /\left(T_{m}-T_{r}\right)$ is the homogenization temperature, $T_{r}$ is room temperature and $T_{m}$ is melting point. The density of AISI 1045 steel is $7860 \mathrm{~kg} / \mathrm{m}^{3}$, and its melting point is $1460{ }^{\circ} \mathrm{C}$. The heat capacity and thermal conductivity are functions of temperature and can be calculated by,

$$
\begin{gathered}
c\left[\mathrm{Jkg}^{-1} \mathrm{~K}^{-1}\right]=420+0.504 T\left[{ }^{\circ} \mathrm{C}\right], \\
k\left[\mathrm{Wm}^{-1} \mathrm{~K}^{-1}\right]=45.48-0.0203 T\left[{ }^{\circ} \mathrm{C}\right] .
\end{gathered}
$$

Table 1. Parameters of J-C constitutive relation for AISI 1045 steel

\begin{tabular}{|l|c|c|c|c|c|}
\hline $\begin{array}{l}\text { Constitutive } \\
\text { parameters }\end{array}$ & $\bar{A}[\mathrm{MPa}]$ & $\bar{B}[\mathrm{Mpa}]$ & $\bar{C}$ & $n$ & $m$ \\
\hline value & 553.1 & 600.8 & 0.0134 & 0.234 & 1 \\
\hline
\end{tabular}

The influences of cutting parameters, including cutting speed, depth of cut, and rake angle, are analysed. Each time one parameter is changed to study its effect while others are fixed and the results are shown in Fig. 7. Fig. 7a gives the influence of cutting speed on adiabatic shear. It can be seen that the adiabatic shear will occur when the cutting speed is larger. The influence of depth of cut is similar with that of cutting speed, as shown in Fig. 7b. Fig. 7c indicates that the adiabatic shear will appear easier when the rake angle is smaller. At the same time, the influence of cutting speed is the biggest, the influence of depth of cut is the second, and that of rake angle is the least. The influence mechanism of these phenomena will be discussed in Section 5.

\section{EXPERIMENT VALIDATION}

An orthogonal cutting experiment was carried out for the validation of the prediction results. The workpiece is a cylindrical tube of AISI 1045 steel with an inside diameter of $151.75 \mathrm{~mm}$ and thickness of 2.5 mm. Fig. 8 shows the experiment device. A cemented carbides YT15 cutting tool (TCMT110204 insert and STFCR1616H11 holder) was adopted. The experiment was done on a CA6140 lathe by dry cutting. The tool was replaced after each experiment for keeping the tool sharp. The range of cutting speed of $V=48.7 \mathrm{~m} /$ $\min$ to $480.7 \mathrm{~m} / \mathrm{min}$, three depths of cut of $a_{c}=0.11$ $\mathrm{mm}, a_{c}=0.15 \mathrm{~mm}$ and $a_{c}=0.2 \mathrm{~mm}$; three rake angles of $\gamma_{1}=10^{\circ}, \gamma_{1}=0^{\circ}$, and $\gamma_{1}=-10^{\circ}$ were selected as the cutting conditions.
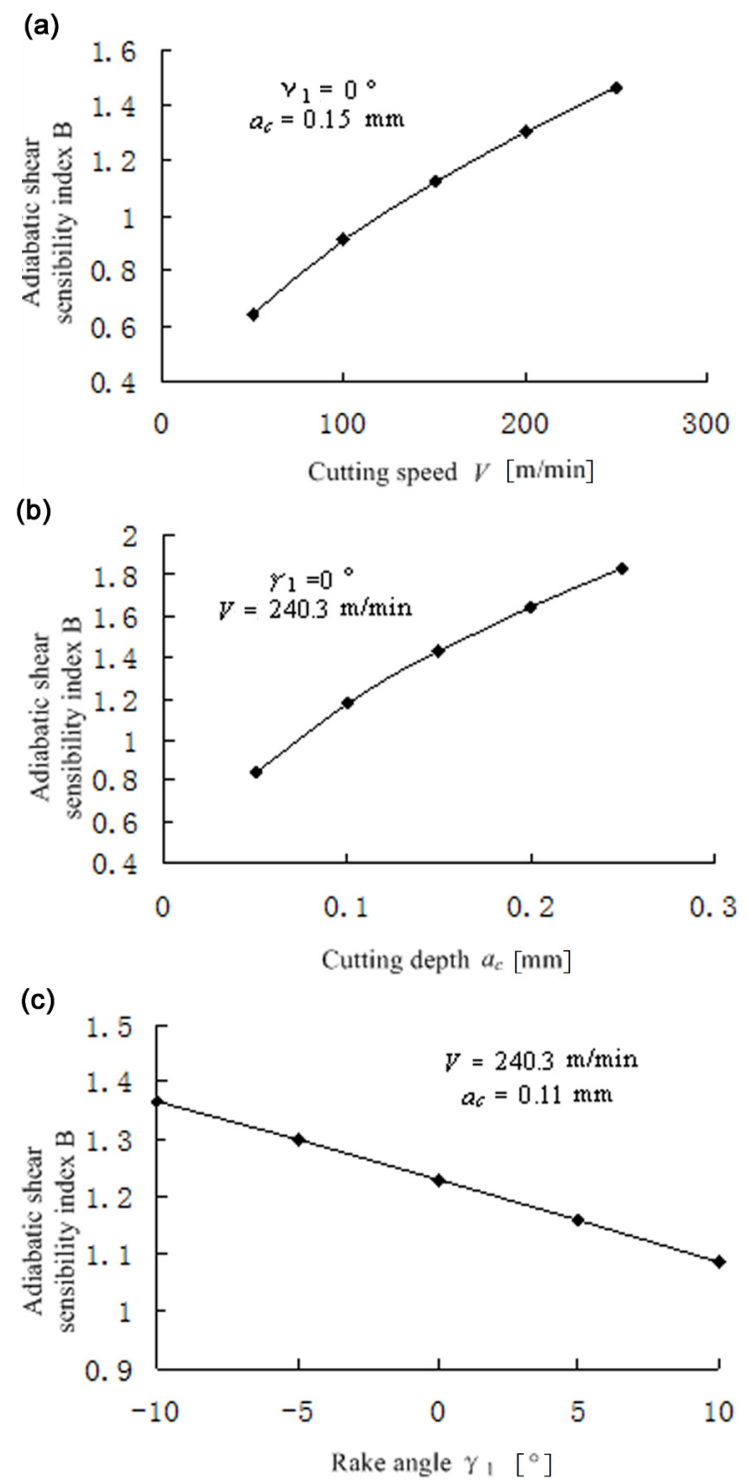

Fig. 7. Influence of cutting conditions on adiabatic shear in HSM: a) influence of cutting speed, b) influence of depth of cut, and c) influence of rake angle

The collected chip was fixed vertically in the admixture of epoxy resins and solidified agent (ratio 
is 1:1) and then the samples (as shown in Fig. 9) were ground to the midsection of the chip. A Neuphot-II type optical microscope was used to observe the chip after grinding, polishing, and eroding.

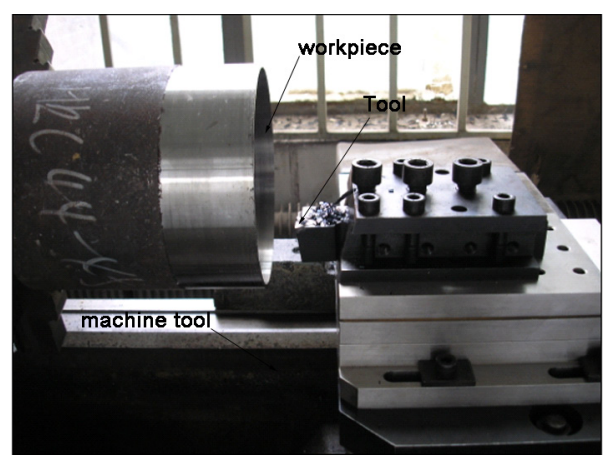

Fig. 8. Experiment device

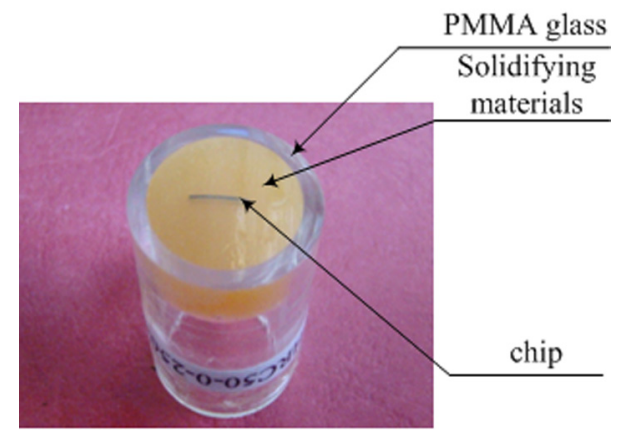

Fig. 9. Observation sample

The influences of cutting conditions on chip morphology are shown in Figs. 10 to 12. It is clear that larger cutting speed, greater depth of cut and smaller
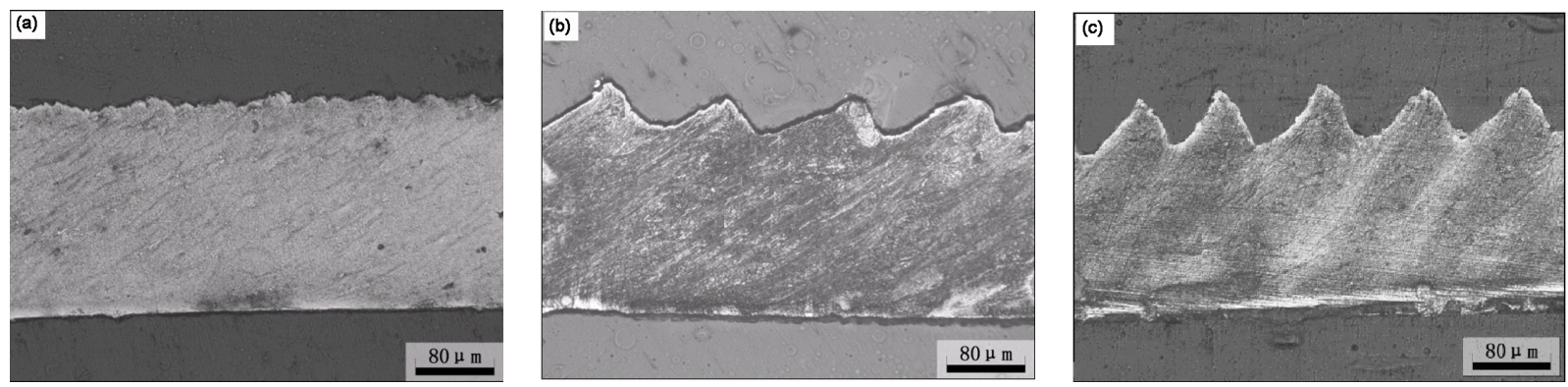

Fig. 10. Influence of cutting speed $\left(\gamma_{1}=0^{\circ}, a_{c}=0.15 \mathrm{~mm}\right.$ : a) $\left.V=96.1 \mathrm{~m} / \mathrm{min}, b\right) V=151.4 \mathrm{~m} / \mathrm{min}$, and c) $\left.V=240.3 \mathrm{~m} / \mathrm{min}\right)$
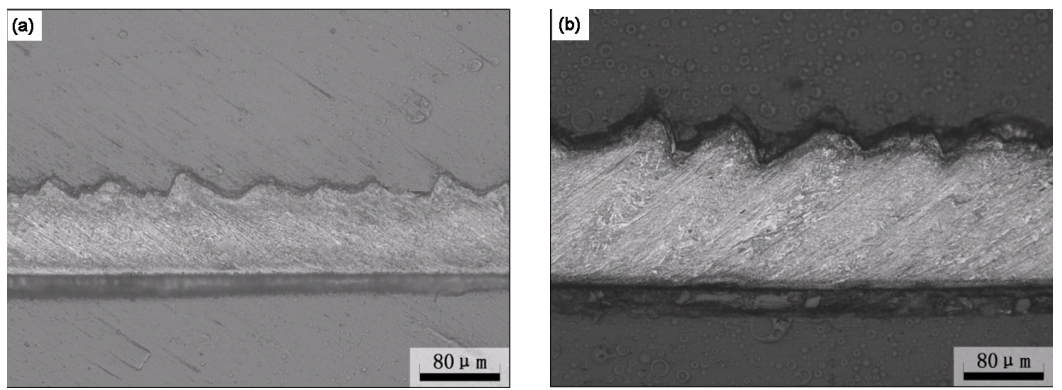

Fig. 11. Influence of depth of cut $\left(\gamma_{1}=0^{\circ}, V=240.3 \mathrm{~m} / \mathrm{min}:\right.$ a) $\left.\left.a_{c}=0.07 \mathrm{~mm}, b\right) a_{c}=0.11 \mathrm{~mm}\right)$
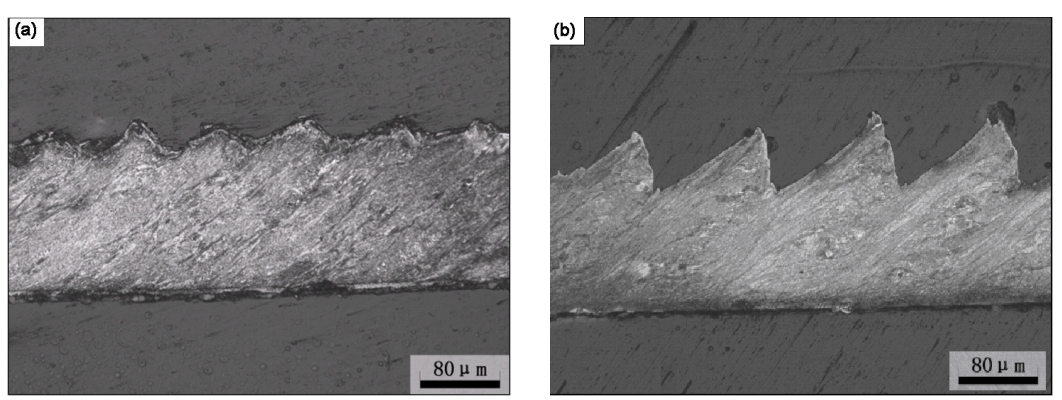

Fig. 12. Influence of rake angle $\left(V=240.3 \mathrm{~m} / \mathrm{min}, a_{c}=0.11 \mathrm{~mm}:\right.$ a) $\gamma_{1}=10^{\circ}$, b) $\left.\gamma_{1}=-10^{\circ}\right)$ 
rake angle will promote the occurrence of adiabatic shear and lead to the forming of serrated chips. These are consistent with the analysis results and show the effectiveness of the proposed model.

\section{DISCUSSION}

The adiabatic shear localization under simple shear is usually explained by the theory of thermoplastic instability (Fig. 13), namely that the competition between strain hardening and thermal softening controls the occurrence of adiabatic shear. When strain hardening exceeds thermal softening, the plastic deformation is steady. Otherwise, the plastic deformation is unstable and the further plastic deformation occurs at smaller stresses until fracture.

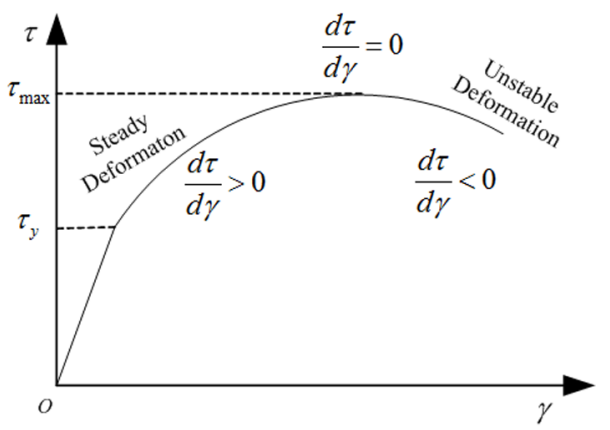

Fig. 13. Thermoplastic instability curve

The influence of cutting parameters on adiabatic shear can be explained by the proposed model. According to Eq. (6), the influence of strain and strain rate on adiabatic shear easily can be explained easily. The results are shown in Fig. 14.

According to Eqs. (8) and (13), the strain rate increases with the increase of cutting speed and the strain decreases with the increase of rake angle. Therefore, the adiabatic shear in machining occurs under the condition of larger cutting speed and smaller rake angle. These influence also can be explained by the above thermoplastic instability theory.

The influence of depth of cut is difficult to explain with the existing theory. Because as the depth of cut increases, the strain decreases according to the cutting theory, and the strain rate also decreases according to Eqs. (8) and (11). According to the theory of thermoplastic instability, the adiabatic shear should occur under smaller depths of cut. This is in conflict with the experiment result. From Fig. 13 , it can be seen that in the zone of unstable plastic deformation, the stress increases with the decrease of strain. According to proposed model (Eq. (6)), this will lead to the increase of adiabatic shear sensitivity index $B$, which means the adiabatic shear will occur under larger depths of cut.
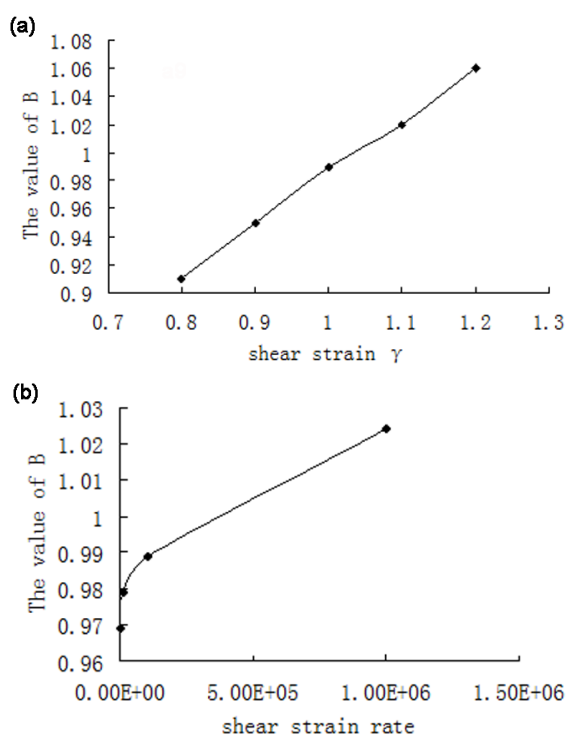

Fig. 14. Influences of deformation conditions on adiabatic shear: a) influence of strain, and b) influence of strain rate

The existing research on adiabatic shear in machining mostly focuses on the influence of cutting speed. Using the proposed model in this paper, not only can the system analysis of the influence of cutting parameters (including cutting speed, depth of cut and rake angle) on adiabatic shear be conducted but a reasonable explanation for these influences can also be given.

Furthermore, researches show that the evolution of adiabatic shear leads to the change of serrated chip, from partial to complete separation. This change will lead to the reduction of tool life, degradation of the machined surface integrity and the reduction of part accuracy. As mentioned in Section 1, the value of adiabatic shear sensitivity index B reflects the degree of adiabatic shear evolution. The relationship between cutting conditions and adiabatic shear sensitivity index B is also established. If the relationship between the evolution of adiabatic shear and the tool life, or machined surface integrity, etc., can be revealed in the future, the optimization of cutting parameters can be realized by combining the proposed model. Therefore, the proposed model can not only deepen the understanding of adiabatic shear in HSM, but also in favour of the optimization of cutting parameters. 


\section{CONCLUSIONS}

- Based on an adiabatic shear sensitivity index proposed by linear perturbation analysis which considers the pressure-shear condition in machining, the relationship of adiabatic shear and cutting conditions are built. The corresponding relation between the cutting conditions and the deformation conditions is established based on the model of parallel boundary shear zone. The proposed model is validated by experiments.

- The adiabatic shear in HSM tends to occur under the condition of higher cutting speed, greater cutting depth and smaller rake angle. Furthermore, the influence of cutting speed is the biggest, the influence of cutting depth is the second, and that of rake angle is the least.

- The proposed model not only can reveal the mechanism of adiabatic shear in high-speed cutting, but can also be used in the optimization of cutting parameters.

\section{ACKNOWLEDGEMENT}

This work is supported by the Innovation Team Training Plan of Tianjin Universities and colleges (Grant No. TD12-5043), Tianjin Science and Technology Innovation System and Platform Construction Plan (14TXGCCX00011), Tianjin Universities "Training Plan of Subject-Leading Personnel" (RC14-02), the project of excellent young teachers (RC14-17) and that of young scholar broad (201307760011). This work is also supported by National-Local Joint Engineering Laboratory of Intelligent Manufacturing Oriented Automobile Die \& Mould.

\section{REFERENCES:}

[1] Ai, X. (2003). Technology of High Speed Machining. National Defense Industry Press, Beijing, p. 1-5.

[2] Barry, J., Byrne, G. (2002). The mechanisms of chip formation in machining hardened steel. Journal of Manufacturing Science and Engineering, vol. 124, no. 3, p. 528-535, DOI:10.1115/1.1455643.

[3] Ye, G.G., Xue, S.F., Ma, W., Jiang, M.Q., Ling, Z., Tong, X.H., Dai, L.H. (2012). Cutting AISI 1045 steel at very high speeds. International Journal of Machine Tools and Manufacture, vol. 56, p. 1-9, D0l:10.1016/j.ijmachtools.2011.12.009.

[4] Vyas, A., Shaw, M.C. (1999). Mechanics of saw-tooth chip formation in metal cutting. Journal of Manufacturing Science and Engineering, vol. 121, no. 2, p. 163-172, DOI:10.1115/1.2831200.
[5] Astakhov, V.P. (1964). Geometry of Single-Point Turning Tools and Drills. Springer London Ltd, London.

[6] Recht, R.F. (1964). Catastrophic thermoplastic shear. Journal of Applied Mechanics, vol. 31, no. 2, p. 189-193, DOI:10.1115/1.3629585.

[7] Komandui, R., Schroeder, T., Hazra J., von Turkovich, B.F., Flom, D.G. (1982). On the catastrophic shear instability in high-speed machining of an AISI4340 steel. Journal of Engineering for Industry, vol. 104, no. 2, p. 121-131, DOl:10.1115/1.3185807.

[8] Davies, M.A., Burns, T.J., Evans, C.J. (1997). On the dynamics of chip formation in machining hard metals. CIRP Annals, vol. 46, no. 1, p. 25-30, D0l:10.1016/S0007-8506(07)60768-9.

[9] Molinari, A., Musquar, C., Sutter, G. (2002). Adiabatic shear banding in high speed machining of Ti-6Al-4V: experiments and modeling. International Journal of Plasticity, vol. 18, no. 4, p. 443-459, DOI:10.1016/S0749-6419(01)00003-1.

[10] Ma, W., Li, X.W., Dai, L.H., Ling, Z. (2012). Instability criterion of materials in combined stress states and its application to orthogonal cutting process. International Journal of Plasticity, vol. 30-31, p. 18-40, D0l:10.1016/j.ijplas.2011.09.003.

[11] Sheikh-Ahmad, J.Y., Quarless, V., Bailey, J.A. (2004). On the role of micro-cracks on flow instability in low speed machining of CP titanium. Machining Science and Technology, vol. 8, no. 3, p. 415-430, D0I:10.1081/MST-200039867.

[12] Sun, S., Brandt, M., Dargusch, M.S. (2009). Characteristics of cutting forces and chip formation in machining of titanium alloys. International Journal of Machine Tools \& Manufacturing, vol. 49, no. 7-8, p. 561-568, Dol:10.1016/j. ijmachtools.2009.02.008.

[13] Huang, J., Kalaitzidou, K., Sutherland, J.W., Aifantis, E.C. (2011). Validation of a predictive model for adiabatic shear band formation in chips produced via orthogonal machining. Journal of Mechanical Behavior of Materials, vol. 18, no. 4, p. 243-264, DOI:10.1515/JMBM.2007.18.4.243.

[14] Duan, C.Z., Zhang, L.C. (2012). Adiabatic shear banding in AISI 1045 steel during high speed machining: Mechanisms of microstructural evolution. Materials Science and Engineering: A, vol. 532, p. 111-119, D0l:10.1016/J.msea.2011.10.071.

[15] Molinari, A., Soldani, X., Miguélez, M.H. (2013). Adiabatic shear banding and scaling laws in chip formation with application to cutting of Ti-6Al-4V. Journal of the Mechanics and Physics of Solids, vol. 61, no. 11, p. 2331-2359, D0l:10.1016/j. jmps.2013.05.006.

[16] Miguélez, M.H., Soldani, X., Molinari, A. (2013). Analysis of adiabatic shear banding in orthogonal cutting of Ti alloy. International Journal of Mechanical Sciences, vol. 75, p. 212222, D0I:10.1016/j.ijmecsci.2013.06.011.

[17] Gu, L.Y., Wang, M.J., Duan, C.Z. (2013). On adiabatic shear localized fracture during serrated chip evolution in high speed machining of hardened AISI 1045 steel. International Journal of Mechanical Sciences, vol. 75, p. 288-298, D0l:10.1016/j. ijmecsci.2013.07.004.

[18] Gu, L.Y., Kang, G.Z., Chen, H., Wang, M.J. (2016). On adiabatic shear fracture in high-speed machining of martensiticprecipitation-hardening stainless steel. Journal of Materials Processing Technology, vol. 234, p. 208-216, D0l:10.1016/j. jmatprotec.2016.03.010. 
[19] Ye, G.G., Xue, S.F., Jiang, M.Q. (2013). Modeling periodic adiabatic shear band evolution during high speed machining Ti-6Al-4V alloy. International Journal of Plasticity, vol. 40, p. 39-55, D0l:10.1016/J.ijplas.2012.07.001.

[20] Ye, G.G., Chen, Y., Xue, S.F., Dai. L.H. (2014). Critical cutting speed for onset of serrated chip flow in high speed machining. International Journal of Machine Tools \& Manufacture, vol. 86, p. 18-33, D0I:10.1016/j.ijmachtools.2014.06.006.

[21] Ye, G.G., Jiang, M.Q., Xue, S.F., Ma, W., Dai, L.H. (2017). On the instability of chip flow in high-speed machining. Mechanics of Materials, in press, p. 1-16, D0l:10.1016/j. mechmat.2017.02.006.

[22] Wang, C.Y., Xie, Y.X., Zheng, L.J., Qin, Z., Tang, D., Song, Y. (2014). Research on the chip formation mechanism during the high-speed milling of hardened steel. International Journal of Machine Tools \& Manufacture, vol. 79, p. 31-48, D0l:10.1016/j.jimachtools.2014.01.002.

[23] Wu, H.B., To, S. (2015). Serrated chip formation and their adiabatic analysis by using the constitutive model of titanium alloy in high speed cutting. Journal of Alloys and Compounds, vol. 629, p. 368-373, D0I:10.1016/J.jallcom.2014.12.230.

[24] Jomaa, W., Mechri, O., Lévesque, J., Songmene, V., Bocher, P., Gakwaya, A. (2017). Finite element simulation and analysis of serrated chip formation during high-speed machining of AA7075-T651 alloy. Journal of Manufacturing Processes, vol. 26, p. 446-458, D0I:10.1016/j.jmapro.2017.02.015.

[25] Wang, B., Liu, Z.Q. (2014). Serrated chip formation mechanism based on mixed mode of ductile fracture and adiabatic shear. Proceedings of the Institution of Mechanical Engineers, Part B: Journal of Engineering Manufacture, vol. 228, no. 2, p. 181190, D0I:10.1177/0954405413497941.

[26] Wang, B., Liu, Z.Q. (2016). Evaluation on fracture locus of serrated chip generation with stress triaxiality in high speed machining of Ti6Al4V. Materials and Design, vol. 98, p. 68-78, DOl:10.1016/j.matdes.2016.03.012.

[27] Wang, B., Liu, Z.Q. (2017). Acoustic emission signal analysis during chip formation process in high speed machining of 7050-T7451 aluminum alloy and Inconel 718superalloy. Journal of Manufacturing Processes, vol. 27, p. 114-125, DOI:10.1016/j.jmapro.2017.04.003.
[28] Li, G.H., Wang, M.J., Duan, C.Z. (2009). Adiabatic shear critical condition in the high-speed cutting. Journal of Materials Processing Technology, vol. 209, no. 3, p. 1362-1367, D0I:10.1016/j.jmatprotec.2008.03.050.

[29] Thé, J.H.L., Scrutton, R.F. (1979). Stress-state in the shear zone during steady state machining. Journal of Engineering for Industry, vol. 101, no. 2, p. 211-216, D0l:10.1115/1.3439497.

[30] Tay, A.O., Stevenson, M.G., de Vahl Davis, G., Oxley, P.L.B. (1976). Numerical method for calculating temperature distributions in machining, from force and shear angle measurements. International Journal of Machine Tool Design \& Research, vo. 16, no. 4, p. 335-349, D0l:10.1016/00207357(76)90043-3.

[31] Li, G.H., Wang, M.J., Duan, C.Z., (2011). Experimental Study of Adiabatic Shear Critical Conditions in Orthogonal Cutting of hardened 45 Steel. Journal of Dalian University of Technology, vol. 51, no. 4, p. 518-524.

[32] Komanduri, R., Von Turkovich, B.F. (1981). New observation on the mechanism of chip formation when machining titanium alloys. Wear, vol. 69, no. 2, p. 179-188, D0l:10.1016/00431648(81)90242-8.

[33] Oxley, P.L.B., Hastings, W.F. (1977). Predicting the strain rate in the zone of intense shear in which the chip is formed in machining from the dynamic flow stress properties of the work material and the cutting conditions. Proceedings of the Royal Society A, vol. A356, no. 1686, p. 395-410, Dol:10.1098/ rspa.1977.0141.

[34] Li, G.H., Wang, M.J. (2009). Calculating of the temperature distribution of primary shear zone in orthogonal high speed cutting based on the non-uniform volume moving heat source. Materials Science Forum, vol. 626-627, p. 105-110, D0I:10.4028/www.scientific.net/MSF.626-627.105.

[35] Karpat, Y., Özel, T. (2005). Predictive analytical and thermal modeling of orthogonal cutting process-Part I: Predictions of tool forces, stresses, and temperature distributions. Journal of Manufacturing Science and Engineering, vol. 128, no. 2, p. 435-443, DOI:10.1115/1.2162590. 